\title{
Networks, Agent-Based Models and the Antonine Itineraries: Implica- tions for Roman Archaeology
}

\section{Shawn Graham}

Department of Classics, University of Manitoba, 360 University College, Winnipeg, Manitoba R3T 2M8, Canada

E-mail: grahams@cc.umanitoba.ca

\begin{abstract}
This paper presents a way of looking at Roman space from a Roman perspective, and suggests ways in which this point of view might open up new approaches in Roman archaeology. It turns on one conception of Roman space in particular, preserved for us in the Antonine Itineraries. Working from a position that considers the context of the itineraries as movement-through-space, this paper presents an investigation using social network analysis and agent-based simulation to re-animate the itineraries. The itineraries for Iberia, Gaul, Italy, and Britain are considered. The results of the social network analysis suggest structural differences in the way that the itineraries presented space to the reader/traveler. The results of the simulation of information diffusion through these regions following the routes in the itineraries suggest ways that this conception of space affected the cultural and material development of these regions. Suggestions for extending the basic model for more complicated archaeological analyses are presented.
\end{abstract}

Keywords: ???

\section{Introduction}

This paper uses computer modeling to understand Roman conceptions of geographic space and the attendant implications for Roman archaeology. It uses a social network analysis to investigate the arrangement of the Antonine Itineraries for regional structural differences. It then 're-animates' patterns of information diffusion on those structures using an agent-based simulation. Certain archaeological patterns seem to agree with the results of the social networks analysis and the simulation. This may be the first study in the Roman world which uses agent-based modeling in this fashion, and so the results are necessarily constrained, but it follows in the tradition of research carried out by Kohler (1995), Kohler et al. (2005), Doran et al. (1994), and Cherry (1977).

(C) The Fund for Mediterranean Archaeology/Equinox Publishing Ltd., 2006
Representing Space

How do we find our way in new territory? We have a particular 'mind map', which hangs on points of our own experiences and our relationships with other individuals and institutions (Gould and White 1974), with which we structure our understanding of space. Kevin Lynch's book The Image of the City (1960) prompted much research into how we conceptualize space. One of the main points is that the construction of space is socially mediated (cf. Urry 2000: 49-76, on the sociology of 'travellings'; Mark et al. 1999). How we represent that socially-mediated understanding of geographic space in turn affects our interpretation of it (Batty 2003; Montello et al. 2003). In tests where subjects are shown scatters of points against a neutral background (something that 
the viewer implicitly recognises as a map), it has been found that the subjects are more inclined to associate points together in the updown dimension than in the left-right dimension-even though the spacing between all the points is the same (Montello et al. 2003: 31637). In modern western culture, we are accustomed to orienting our maps so that north is always at the top (by default, then, as viewers we are prioritizing relationships in the up-down dimension, which may not be warranted). If understanding space is so complicated in the modern world (what we understand is based on our experiences; how we represent what we understand in turn affects our understanding), it is doubly so for understanding an ancient conception of space.

For antiquity, Favro (1996) connected the Roman orator's 'house of memory' to a way of reading the Urban Image of Augustan Rome, for understanding the interconnections and meanings between places in the city (following Lynch 1960). Using a 'stranger in town'-Pompeii-as an example, Ling wondered how visitors to a new town might find their way (they would have to use ad hoc directions based on recognisable landmarks). The recent volume on Travel and Geography in the Roman Empire (Adams and Laurence 2001) explicitly considers the Roman representation of large-scale geographic space, as opposed to these smaller, urban representations. For the Roman, large-scale geographical space was often viewed as a list, of what-comes-next. The most famous of these lists today are the Antonine Itineraries (Salway 2001; Brodersen 2001; Arnaud 1992; Capelli and Pesando 1991). Details about the space between places could always be supplied by a knowledgeable local, but the global perception was courtesy of a list, an itinerary. The success of one's journey depended on the quality of the itinerary at hand: see, for example, Galen's misadventures on his way to Lemnos in the 2nd century $A D$ (discussed by Brodersen 2001: 8-9).

\section{The Itineraries}

The Antonine Itineraries are a collection of routes within the Empire, with the starting and ending points and intervening stages along the routes listed with the appropriate mileages between stages indicated. There are breaks in the sequence which imply that up to 10 separate smaller itinerary lists were collated to create the collection. These routes of travel do not necessarily map exactly onto the Roman road system (and sometimes they imply a certain amount of river-travel). There are in fact a number of maritime itineraries included, which follow the Greek tradition of mariners' coast-line descriptions, the periploi, and probably have their sources in these as well. These sections measure distance in Greek stadia, although some use miles instead. Some itineraries listed seem to suggest that a real journey was recorded and incorporated, perhaps a journey of an Emperor Antoninus. The omission of places in the Agri Decumantes or in Dacia point to a compilation date sometime after the abandonment of these regions in the latter half of the $3 \mathrm{rd}$ century $\mathrm{AD}$ (Salway 2001: 26-43).

Salway discusses how the lists were compiled from milestones and other public displays of stages and distances, how they are 'very much rooted in the experience of travel rather than the theory of geography' (Salway 2001: 58). Who was the traveller? This question is tied up with how the itineraries were compiled from other documents: 'These instruments of public display meet the needs of the private individual forced occasionally to make journeys beyond the region with which he or she is normally familiar. Such a constituency will have changed over time.' (Salway 2001: 59).

Salway concludes that the final compilation of these documents from different periods into the itineraries as we know them in the 4th century AD reflects the need to be able to find one's way to whatever city the Imperial Court 
happened to be at (Salway 2001: 60). They reflect the experience of local geographies stitched together for a particular purpose that may not reflect the multifarious purposes for which the original texts (inscribed in stone, erected in town centers, and so on) were used. But they do, at bottom, reflect some of the realities of traveling around the lands controlled by Rome. It is in this bottom level that I am interested. What do the surviving itineraries suggest for how geographic space was organized and experienced in the Roman world? I take a philosophical view of the itineraries, informed by the writings of the landscape architect Anne Whiston Spirn. Spirn reminds us that the context of landscape is 'process', pointing out that the word 'context' has an active, Latin root: 'contexere', to weave. She writes:

Context weaves patterns of events, materials, forms, and spaces... A river, flowing, is context for water, sand, fish, and fishermen; flooding and ebbing, it shapes bars, banks, and valley. A gate is context for passage, its form determining how things flow through it: narrow gates constrict; gates of screens block large things and permit smaller ones to pass through. Context is a place where processes happen, a setting of dynamic relationships, not a collection of static features. (Spirn 1998: 133, emphasis added).

From this point of view, the itineraries are not simple lists: they are records of journeys, both real and potential, across the vast landscape of the Roman Empire, and they are the static presentation of dynamic relationships between the towns listed. These relationships were the normal comings and goings associated with trade, with extended families, with culture which exists between any two neighbouring settlements. Accordingly, in this paper I consider the itineraries first from a static, and then from a dynamic, point of view. I adapt an existing methodology from sociology and explore a developing methodology from computer science, for understanding the conception of geographic space as recorded in the Antonine Itineraries. I then suggest some of the implications for our understanding of the geography of the Roman Empire in light of the social structure of that space, and ways this understanding might usefully be employed in landscape archaeology.

\section{The Starting Point}

My starting point is Laurence's (2001) recent work on the Romanization of Britain. He uses the evidence of the itineraries to compare different provinces' space-economies. 'Spaceeconomy' is based on the idea that good, allweather roads allowing easier travel between areas created a new conception of space, shortening the temporal distance between places. In Italy, the net result was its unification (Laurence 2002).

Laurence was interested to see if the distances recorded in the itineraries for Britain were similar to those around the Mediterranean, and if the geography of Britain was organized along similar lines. He calls this 'the infrastructure of Imperialism' (Laurence 2001: $67,74-75)$. Focusing on the mileage between centers, Laurence (2001: 90-91) concludes that the 'connectivity' of Britain was not significantly different from the Mediterranean world. He argues that this is a better measure of the Romanization of Britain, of its incorporation into the Roman world, than the monumentalization of urban centers. It is worth pointing out that Laurence's 'connectivity' focuses exclusively on the distances between places-the mileages-rather than the overall patterning of the connections themselves, an important distinction (see further below). Laurence (2001: 91) takes the view of Horden and Purcell (2000) in their work The Corrupting Sea, which emphasizes understanding the Mediterranean world from an ecological point of view, and in terms of flows of people, capital, and goods. 
Laurence's approach is a novel development, at least as far as it goes, but it is static and does not focus on the actual patterning of interconnections (the topology). It would be better if we could actually use the itineraries for ourselves, to guide our navigation of the Empire, and to experience this Roman view of space. Would we find the same results as Laurence? What would be our perception of the different provinces? What would be the aggregate perception of the different provinces? Would there be something at that level, different from our individual perception? This is where the methodologies of Agent-Based Modeling and Social Network Analyses can usefully be employed. The discussion here is restricted to the itineraries which cover Britain, Gaul, Iberia, and Italy, leaving aside the eastern end of the empire. The itineraries considered here follow those of Cuntz (1929).

\section{Social Networks, Town Networks, and the Itineraries: Static Space}

In 1931, Henry Beck invented the modern London Underground diagram that now guides millions of people's navigation of London. By ignoring 'real-world' geography, and placing stations so that their relationships one to another were clearly evident, Beck made a 'network diagram' map that simplified the (daunting) task of getting around the metropolis (Brodersen 2001: 18) — that is, his 'map' is a topological representation of the connections between places. This is the heart of Social Network Analysis (Hanneman and Riddle 2005), the body of methodologies used here to analyse the implications for the human geography of the Empire based on the Antonine Itineraries

\section{Metaphor and Theory}

Simply put, a social network is one in which the connections between actors (however defined) is a social one. Social network analysis has its foundations in the mathematics of graph theory, which considers sets of connected objects. It is predicated on the idea that overall network shape affects both the options open to individuals (connections facilitate action, absence of connections prohibits actions), and how a particular society as a whole behaves (see Graham 2006a, on social networks in the central Italian brick industry). The network approach necessarily assumes that the network under consideration is static, representing a particular moment in time (but on evolving networks, see Barabàsi 2002; Barabàsi and Albert 1999). Approaches developed from graph theory analyse the ties between actors, in order to determine, amongst other things, which actor is better connected to the others (and so in a position of social power), which actor forms a link between otherwise disconnected clumps of actors (and so forming a social bridge), or how clumps of individuals connect to ever-wider social groupings (group dynamics). Based on their positioning within a network, vis-à-vis other actors, one can determine which actor would wield the most influence over others, or manage the most information flow. This is an approach which has been used successfully in terms of ancient history for prosopographical and geographical studies, where the implied linkages between actors have been some sort of real-world foundation (Kendall 1971; Remus 1996; Duling 1999; Clark 1992; Müller 2002; a seminal work on this type of geographical thought is Chorley and Haggett 1969).

The 'network' can be a powerful metaphor. The urban geographers Massey, Allen, and Pile (1999) use it to understand the interrelationships between people living within cities and, at a higher level, the interrelationships between cities themselves. They argue that examining how social processes extend beyond and also intersect within cities is to say that social processes work across various networks. Cities are the foci of multiple 
networks. Networks extend beyond the city, linking different cities together in different ways, but also incorporating every point in between along the continuum of settlement types, from humble rural farmsteads upwards. According to this model, it is cities themselves which are nodes of social relations in time and space (Massey et al. 1999: 100-136). At all times, however, people must be taken into account: it is not enough that interconnections should exist. Rather, people must make something of these interconnections (Massey et al. 1999: 121). That is, in studying the interrelationships of cities, we have to formulate that interrelationship at the level of individuals. This problem is resolved by considering what flows through these networks-information, commerce, and culture-and the agents who carry those flows. In the agent-model discussed below, the transmission of information is explicitly considered to be through the agency of individuals.

The itineraries represent a type of social network, and they represent one instance of the various possible networks suggest by Massey et al. (1999).To turn these itineraries into a network that we may study needs some sort of formalization of the relationships between the listed towns. In order to keep the analysis simple, we can presume that towns listed one after another in an itinerary have an implied link between them (a foundational observation for Cherry's [1977] study of the political geography of the Mycenaean kingdom of Pylos, and for Kendall [1971; 1977], using networks and graph theory for geographic analysis). Simple geographical proximity implies a certain amount of trade and cultural contacts. Presumably, towns listed together would be more alike socially than towns at either end of an itinerary. This is not to say that neighbouring towns will perform the same role in a society, but rather that they will share cultural and social contacts which, in the main, are more similar than they are different.
Not every possible settlement, however, was listed in the itineraries. The compiler chose which towns and which routes to include, implying that something more than simple geographic space was a factor in how the towns were listed. This is why it makes sense to consider the itineraries as a social network. We can analyse the entire network of towns in the itineraries for a global view of how the Empire was connected. By formalizing the structure of the itineraries in a network, we can study the relative positioning of towns and cities vis-à-vis each other. The structure of the itineraries is a mirror for the structure of Roman urban society (at the regional level) at least as it was conceived by the individual who compiled the lists. Although beyond the scope of the current study, the towns left out of the itineraries could also be considered. A study comparing the topologies of the real road network against the topology of the itineraries would go a long way toward putting the itineraries in their proper context and would allow us to judge whether the emphasis we place on the itineraries is warranted.

\section{Analysis}

In the itineraries, when stitched together, we begin to see the overall pattern of connectivity for the Empire. The towns and settlements form the 'nodes' of the network, the connecting points, and the links are the spaces implied by the settlements' positioning in the list. Towns listed consecutively in the itineraries are joined by single links (Figure 1). Before looking at individual provinces, let us examine the whole empire. There are over 500 towns or cities listed in the Antonine Itineraries (plotted as a network in Figure 2). I use a program called UCINET (Borgatti et al. 1999) to analyse the networks; much of what follows could not possibly be studied other than with a computer. The distance between any two settlements in the empire-wide network ranges from one link (for adjacent towns) to 
Table 1. Average path-lengths by region in the Itineraries considered as a social network. Computed using Ucinet (Borgatti et al.1999). The algorithm considers every possible pair of settlements in turn, and determines the shortest possible path through the network connecting them. It then takes the average of these shortest paths for each region. Each link in a path is the implied step in the itineraries (i.e. if an itinerary were 'Rome-Falerii-Horta', the dash between Rome and Falerii equals one step in the path; Rome links to Horta in two steps).

\begin{tabular}{lccc}
\hline Region & Average Path Length & Longest Path & Cohesion $^{*}$ \\
\hline Italy & 5.1 & 11 & 0.254 \\
Spain & 5.4 & 12 & 0.251 \\
Britain & 5.8 & 12 & 0.138 \\
Gaul & 4.9 & 14 & 0.07 \\
Empire as a Whole & 18.6 & 69 & 0.013 \\
\hline
\end{tabular}

* 0 = not cohesive; 1 = perfectly cohesive

a maximum of 69 links. The shortest average path between any two settlements in the empire-wide network is about 19: that is, if we select any two towns at random, on average there will be a route connecting them by way of 18 other towns (Table 1 ).

Path-length in the itineraries is significant on a number of accounts. First, there is the seeming regularity of the average path-length in each region studied. This would suggest that there is a great deal of internal homogeneity in each region (the closer settlements appear on the itinerary, the more likely they shared cultural traits). This contrasts with the path-length for the empire as a whole, which points to the great diversity within it. Yet to what degree is path-length significant? One is cautious of coincidences: could the regularity be a by-product of the compiler's methodology? It is doubtful whether the regularity observed here was intentional, because it is only evident when viewed from a social network analysis.

A more significant statistic may be the cohesion score, since this is dependent on inter-linkages in the routes themselves. 'Cohesion' in this context means the proportion of links that exist in the network compared to a network with the same number of nodes, where the nodes are all completely connected

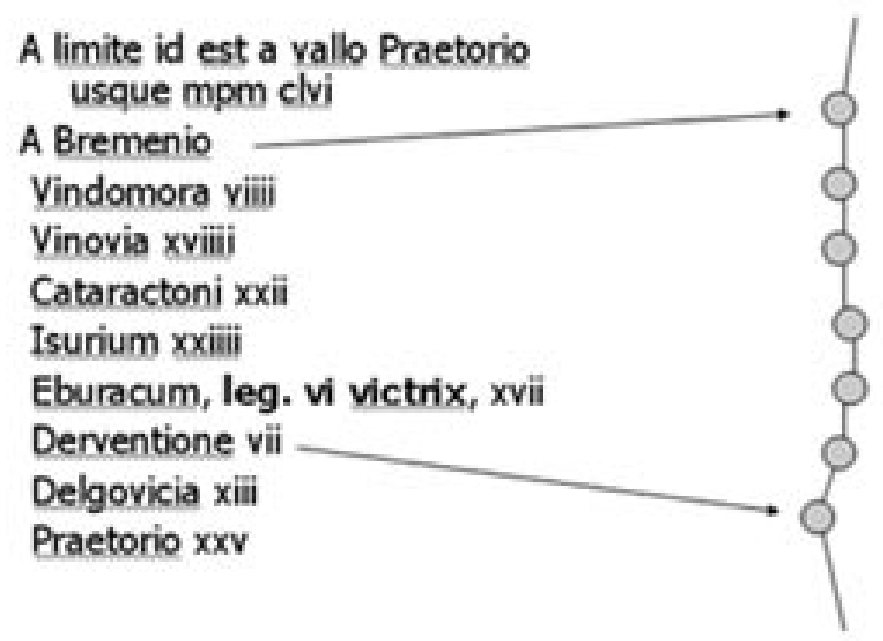

Figure 1. Converting an Itinerary into a social network. This example is a portion of Iter 1 in Britain. Each town or settlement forms a 'node' in a network; the implied step between adjacent towns becomes the 'link'. 


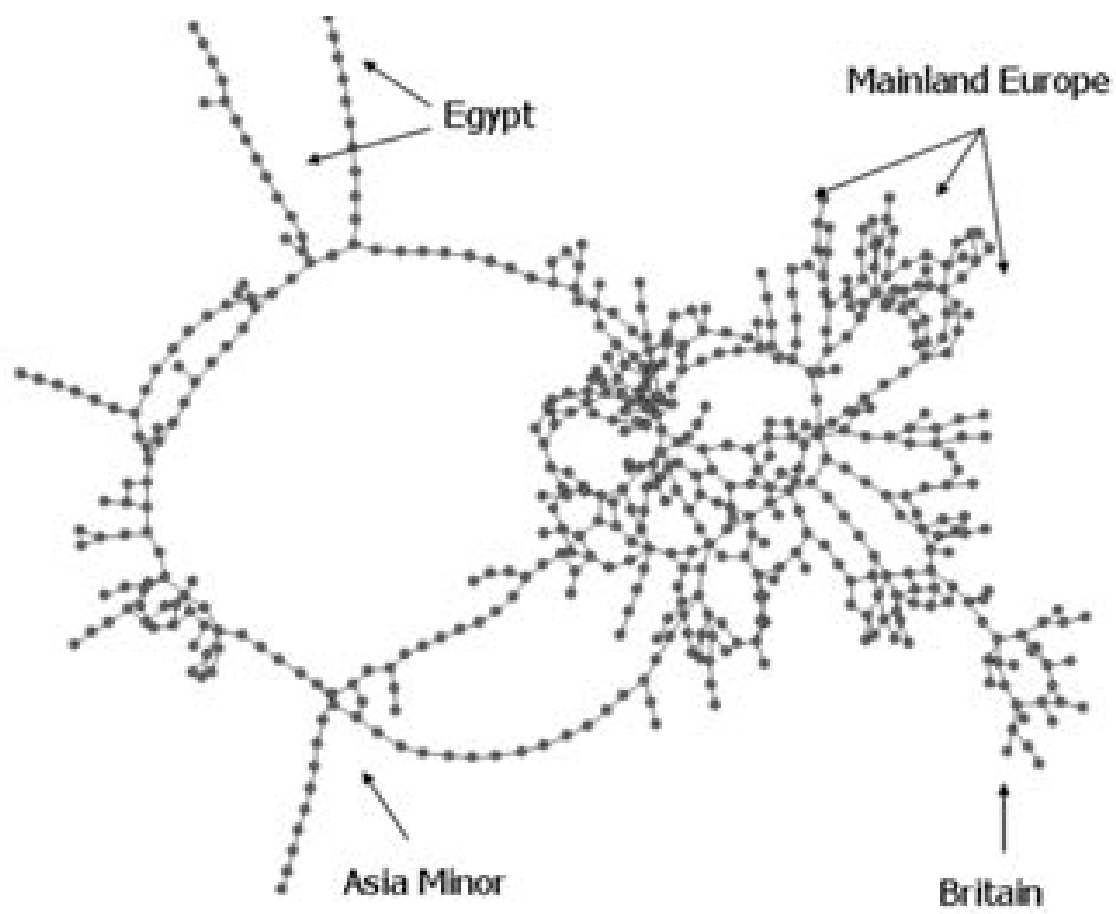

Figure 2. The complete Antonine Itineraries as a social network. There are over 500 'nodes' in the network. The Netdraw program (bundled with Ucinet: Borgatti et al. 1999) sorts the network to obtain a 'best-fit' to make the majority of relationships clear. This can have the effect of creating 'bunches' where nodes that share many similar ties tend to obscure each other in the resulting display.

to each other. On this score, Italy and Spain appear to be very similar, while Gaul is not very tightly knit; in fact, it is an order of magnitude less cohesive than Italy, Spain, and Britain. This perhaps reflects the importance of major rivers for the history of settlement in Gaul, and the stringing-out of settlements along their banks. The Empire as a whole is almost another order of magnitude less cohesive again, no doubt due to the small number of itineraries that include sea travel (on which more below). The cohesion score points to a more interesting phenomenon than pathlength: the idea that networks can fragment.

One could imagine that the perception of fragmentation would have a real impact on a traveller's journey. Roman travellers would not necessarily have known the actual physical routes between places on the list: they would only know that to get to D, they had to go by way of A, B, and C. Using these lists, however, they could count on one link equalling one day's journey (cf. Laurence 2001: 82-86, where the average mileage between places ranges between 17 to 25 miles). Our Romans' trip to D would take four days. What if, for some reason, they felt they could not go through place B? Would the trip still seem feasible? How much fragmentation was possible before the lists were unusable for planning a journey? Considering network fragmentation enables us to return to Laurence's original question and allows us another metric to compare the experience of geographic space. 'Fragmentation' here means anything which could create the perception (whether accurate or not) that a particular route was blocked, that a link in the chain was broken. Anything from rumours of plague, to civil unrest, to the simple desire to avoid a certain individual 
resident or family could cause this perception. Using Keyplayer (Borgatti 1999), a social networks analysis tool, we can investigate how many 'nodes' (connecting points) can be removed before the network collapses into isolated components (i.e. there are no more complete routes).

When the fragmentation curves are plotted (Figure 3), Britain and Gaul have roughly the same curve, while Italy and Iberia share roughly another curve. These fragmentation curves represent the percentage of disruption of the network into isolated segments caused by the removal of the best-connected settlements. Laurence (2001: 90) found that, based on the mileages between places in the itineraries, Britain had a 'Mediterranean' pattern of interconnectivity. But while the mileage might well be similar, the actual shape of those interconnections-the topology-is not. These networks, remember, are proxies for understanding the internal unity of different provinces. Iberia and Italy show a much stronger internal unity than Britain or Gaul. The fragmentation curves demonstrate that the perception of disruption would be rather easy to generate. In Britain, for instance, if London (which the Keyplayer programme identifies as a significant node) seemed for whatever reason to be a 'no-go' zone, the entire network would be disrupted by one-third. If one felt that to get to point $\mathrm{B}$ one had to go through London, this curve indicates that a third of the time, this journey would appear to be impossible. Overall, the way the communications network is presented in the itineraries would make communications seem to be fragmented, even given very low levels of disruption.

The well-known case claimed to exemplify the high costs of land transportation-the

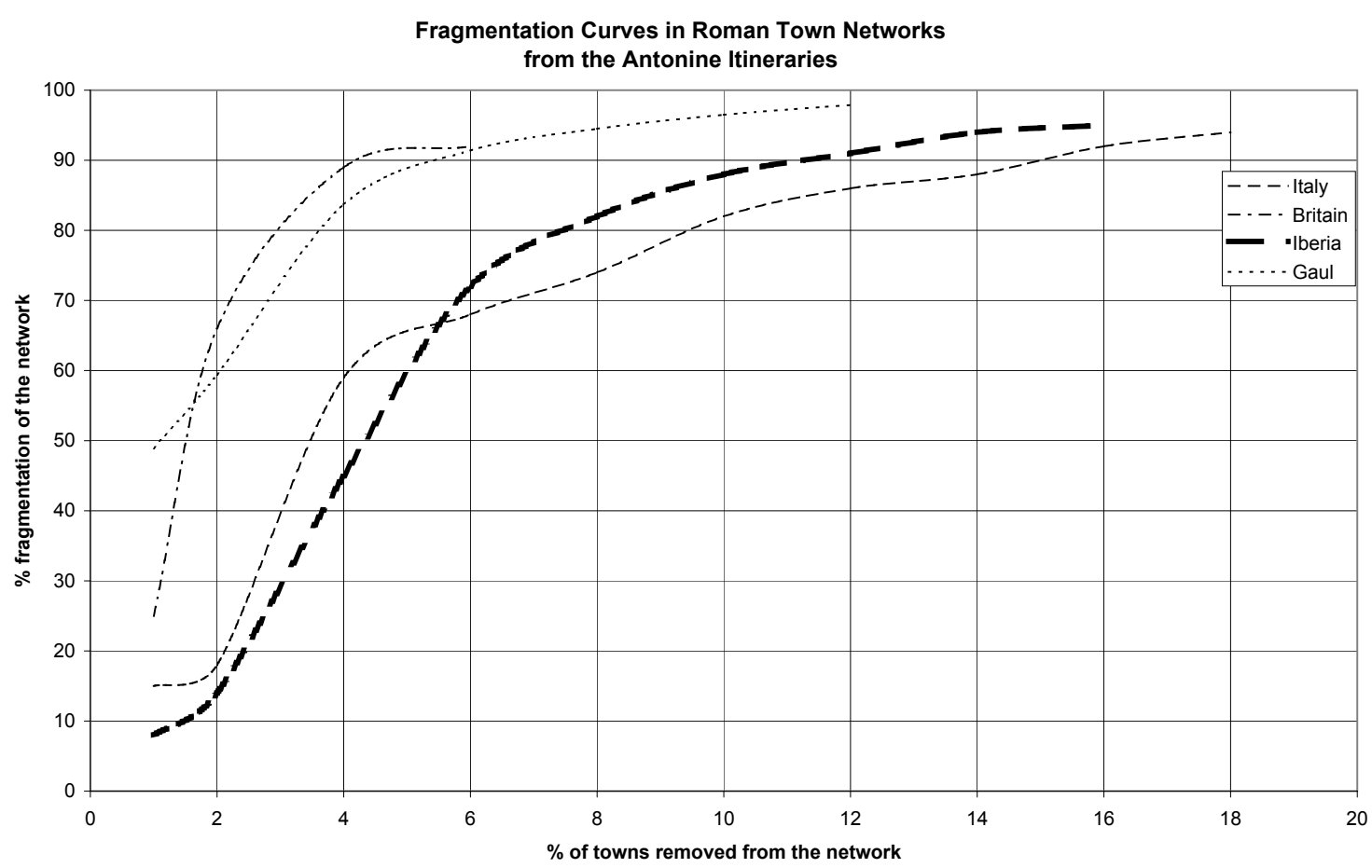

Figure 3. Fragmentation curves for selected regions based on the relevant itineraries considered as social networks. The algorithm calculates the degree of fragmentation the removal would cause of the best connected node, then the two best, then the three best, and so on. 
famine at Antioch, even though grain was available only a short distance away-has been rightly dismissed by Laurence (1998: 135) as a failure of political will rather than of transport costs. We might speculate that a lack of political will could be connected with the nature of geographic knowledge. If there was a perception of disruption, for whatever reason, then alternative routes would have to be found. If a traveller's geographic knowledge was based on these itineraries, there would be great difficulty in planning an alternate route and, more importantly, each alternative step would add another day's travel time. There would come a point-quickly, in the case of Britain - where a journey would seem impossible, or not worth the effort. This has obvious economic implications, especially as we are concerned with land-travel for the most part. We can speculate that some historical events as well might have had cognitive-geographical dimensions to them: for instance, one could imagine that the time necessary to undertake the various 'marches on Rome' to seize power made by ambitious military commanders would only have seemed feasible from certain locations in relationship to the locations of rivals.

To sum up the argument so far: with regard to the social network analysis, different internal structures of provincial communications can be deduced from the itineraries. These internal structures will have implications for how information was disseminated, for the adoption of different kinds of material culture, and indeed for the development of political cultures.

\section{Agent-based Modeling and Simulation: Dynamic Space}

How can we explore some of these implications? One approach would be to use the newly emerging methodology of agent-based modeling (for an introduction to the topic, see Gilbert and Troitzsch 2005: 172-216). Agent-based modeling, also known as individual-based modeling (Gimblett 2002: 5), is theoretically attractive, because it is explicitly concerned with individual agency. In a review of quantitative methods in archaeology in general, Aldenderfer (1998: 91-120) devoted an entire section to what he called 'the return of whole-society modeling'. He attributed the decline of whole-society modeling (where the investigator is trying to create a model which captures the complexity of the entire society in question, typically using differential equations to describe the behaviour of entire 'subsytems') to the collapse of the systems approach and the rise of theoretical positions which emphasized the primacy of the individual (Aldenderfer 1998: 104).

Systems theory emphasized equilibrium, where the interrelationships between the various systems were known (or presumed to be known). Research in other disciplines, however, from mathematics and computer science to biology, found that most systems are not in equilibrium, but are unstable: the interrelationships are not well known, they can change (they are historically contingent), and they exhibit non-linear dynamics. In short, they are complex (Aldenderfer 1998: 104; for general discussion, see Lewin 1993; Cilliers 1998). In human terms, the actions of individuals based on imperfect local knowledge after thousands of repetitions combine to produce results that are unforeseen, potentially undesirable, or even completely contrary to what a given actor may have expected. Agent-based modeling, as an outgrowth of this newer perspective, humbled in the face of complexity, therefore makes no claims as to what global behaviours may be exhibited by a model, but rather concerns itself explicitly with the behaviour of heterogenous individuals. The beauty and value of agent-based models is in exploring what emerges from those interactions. Barrett (2001:155) writes that 'the social totality should 
not form the basic domain or unit of archaeological study... as individuals learn so they make society' (emphasis in original). Individual learning is a hallmark of an agent-based model.

In an agent-based model, individual autonomous software agents are given rules of behaviour, drawn from the social phenomenon we wish to model; then we let the agents interact with each other and their world (that is, they learn), according to the rules we have defined. We build from the bottom-up and from individual behaviour, rather than from formal descriptions of 'sub-systems' (Bonabeau 2002: 7280-81). From all of these countless iterated interactions, larger-scale behaviour (an artificial society) begins to materialize. This description is not meant to minimize or underestimate the practical difficulties in developing such models, but it captures the essence of the process. ${ }^{1}$

Generally, the simpler the rules, the easier it is to validate model results, and for the model results to have a wider applicability. It is crucial to get the rules right. A model may exhibit interesting behaviour, but if the basic rules do not conform to some 'real-world' behaviour we have identified, then the ultimate validity of the model is in doubt (Agar 2003). It is also very important that the 'inner workings' of the model can be inspected by others. This was a problem for model builders in the late 1970s and 1980s, who often had to use very specific languages built for specific problems (Aldenderfer 1991: 203). Very few people had the necessary training realistically to critique the model code itself. This is admittedly still a problem, but one that can be addressed simply by making the approach better known, and encouraging others to explore the possibilities of these models. The ready availability of computing power and the development of open-source multi-purpose simulation environments such as Netlogo and Swarm (which have an easy learning curve and also allow users to 'tinker' with the inner workings of models) have removed many of the obstacles that have impeded simulation modeling in the past. There is also a developing literature on the 'art' of agent-model building to guide the neophyte and to create comparable standards of work (Agar 2003; Gilbert and Troitzsch 2005; Richiardi et al. 2006).

\section{The Rules}

In the rather simple simulation presented here, what is being tested is the effect of different patterns of connectivity on the diffusion of information. I am moving from a static exploration of the itineraries to a dynamic one. In the simulation, each individual 'agent' is distinguishable by its starting place on the network, and its receptiveness to 'hearing' a message. It is not very smart; it either has heard a 'message', or it has not. That is all it knows about its world.

Does it matter what the 'message' is? Not really, since the purpose of this simulation is to explore the flow of information. We could imagine that the message is a new religious practice, or a new style in pottery making; whatever it is, it is secondary to the journey and is not the reason for the journey itself. This agent then travels through a region, following the pathways laid down in the itineraries. Other agents are traveling as well. Because each agent does not necessarily know the 'best' local route to get from one town to another along the itinerary, there is some randomness in the exact path each agent takes. In the two-dimensional simulation world, each route in an itinerary is modeled as a thick line against the map of the region, which makes it possible for two agents, traveling in opposite directions between pairs of towns, to pass each other without actually coming into contact (this allows the model to take into account the discrepancy between global and local forms of geographic knowledge: Graham 2006b). When an agent who has not 'heard' the idea does come into contact with the 'carrier' (they 
collide), the idea is passed along and we now have two carriers, spreading the idea. These are the only rules in this model-move along the path of the itinerary; pass the message to agents who have not heard it.

Are these realistic rules? For the purposes of this model, it is not necessary for us to know how actual Romans transmitted knowledge one to another, or whether this knowledge was contested or transformed in the transmission; it is enough to know that it happened. We should not add any more complexity to the model than what is necessary. 'Necessary' is the key word, and is of course debateable. ${ }^{2}$

\section{Analysis}

I ran the simulation 20 times for each region, with 200 agents each time and the chance of successful transmission set at $100 \%$. The model produces graphic output, with the underlying data being exported to a spreadsheet. Each region is then compared against the other, based on the relative speed of transmission. Time in the model is defined in cycles. Each cycle is completed when every agent has run through its entire set of instructions. It would be possible to calibrate these cycles roughly against known travel times in antiquity, based on the network structure of the itineraries and the various notices in the ancient literature on the speed of communications. For instance, in the consideration by Duncan-Jones (1990: 22-23) of the speed of communication for double-dated edicts from the Theodosian Code, he notes five instances of communications between Gaul and Italy where the average number of days was 39 . This is 20 more days than the shortest average path between any two settlements in the empire-wide network discussed above, and so gives a rough indication that one link in network terms equals two days' travel (see Duncan-Jones 1990: 7-29 on the caveats involved, principally the effects of seasonality). For the purposes of the present

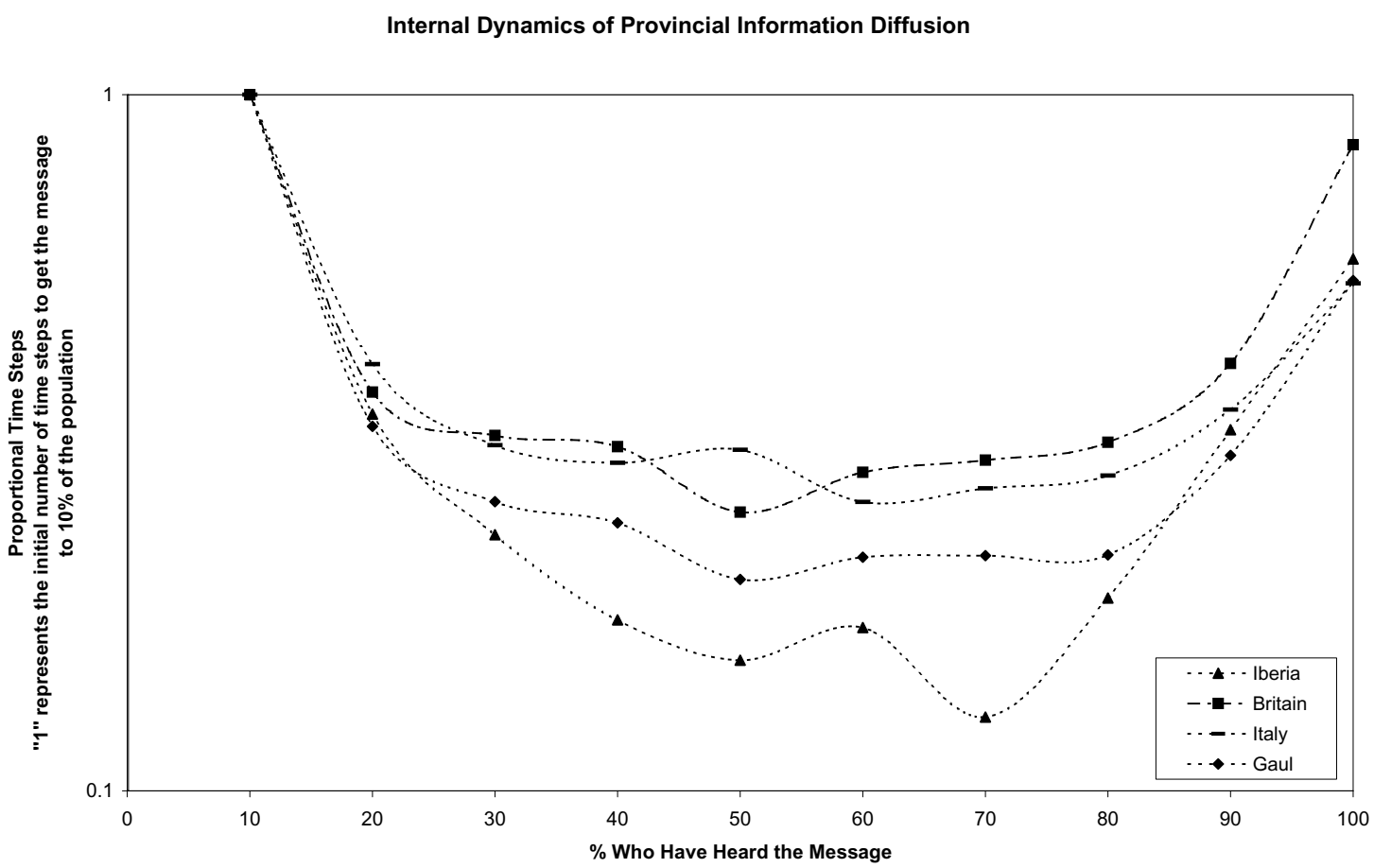

Figure 4. Internal dynamics of information diffusion along the Antonine Itineraries. 
model, this added level of complexity was not necessary, but it does indicate that the effects of network fragmentation could have been even more pronounced than were indicated above.

Because no other variables are modeled in the simulation except the number of travelers, and the chance of an encounter provoking a transmission is guaranteed, the speed of transmission is therefore dependent on the structure of the itineraries themselves. Every region followed a broad pattern (Figure 4). It takes a bit of time for the first $10 \%$ of actors to encounter the 'idea'. Thereafter, diffusion speeds up markedly compared to that original $10 \%$, until roughly half of all agents have encountered the idea. Finally, the diffusion rate slows down, as the last few who have not encountered the idea collide into those who have (some of whom will have heard it several times, a reinforcing process which could be explored in a more sophisticated model).

Italy and Iberia exhibit curves of similar shape, with a deceleration around the 40\% mark (an up-turn of the graph), followed by another period of acceleration, and then the afore-mentioned final deceleration. Britain and Gaul have a constant rate of diffusion after the initial acceleration, and then show another spurt (a down-turn of the graph), before returning to the original rate; they too finish with a final deceleration. Iberia, the largest geographic region studied, has an interconnected structure which makes it the fastest region (internally).

The meanings of this graph are complicated. There are at least two dynamics implied: one by the curve shape (the fashion by which information is diffused), and the other by the curve speed (how quickly the information penetrates). Generally, we can say that in terms of the transmission of knowledge, network shape has a distinct effect on how that knowledge is diffused, pointing to regional differences in the conception of space. Taking this one step further, it points to fundamental differences in the way knowledge spread, and therefore structural geographic differences in culture. Not every place in the Empire shared a 'Mediterranean' pattern of connectivity, Laurence's (2001: 91) alternative for 'Romanization'.

At least so far as the western provinces are concerned, there are distinctive regional differences apparent in the itineraries; but as to which group a particular region belongs, this depends on one's point of view-serving to reinforce Laurence's argument. The graph of the internal speed of British diffusion, while of a different shape than Italy's, shows the same order of speed. Gaul's graph is comparable to Iberia's, though also of a different shape (remembering that 'speed' is not absolute speed, but internal speed as a function of how long it took for the first $10 \%$ to encounter the idea, within the model). Sometimes things look Northern; sometimes they look Mediterranean.

\section{Discussion}

Combining the results of the structural, static approach of social network analysis with the internal dynamics approach of simulation, it would appear that

1. Britain and Gaul are more 'fragile' and less cohesive than Iberia and Italy in terms of network fragmentation.

This might indicate distinct Northern (ignoring for the moment that Gaul has a Mediterranean coastline) and Mediterranean patterns of connectivity, with the provinces of the Northern grouping less well known to the compiler or, alternatively, simply with fewer known routes to get from $\mathrm{A}$ to $\mathrm{B}$. One consequence might be that the perception of disruption would be more difficult to overcome, and for alternative routes to be found. The perception of disruption could carry economic or political costs.

2. Britain and Gaul share the same-shaped internal information diffusion curves, with a 
pronounced downward 'bump' in an otherwise constant trend.

3. Italy and Iberia share a similar-shaped diffusion curve, with a pronounced upward 'bump'.

These 'bumps' suggest some concentrations and 'holes' in the way contacts are mediated. An upward bump in the graph suggests a 'hole', in that new individuals who have not encountered the 'message' are hard to find, thus slowing transmission, while a downward 'bump' suggests a concentration of individuals who have not encountered the 'message', and so transmission rapidly accelerates once the message reaches this cluster.

We could expect a degree of internal homogeneity between regions with similar diffusion curves. This could suggest that for pan-Empire phenomena (e.g. the Imperial Cult), the adoption rate of the innovation would be similar in Britain and Italy, and different from that for Gaul and Iberia. ${ }^{3}$

4. Iberia has the fastest internal diffusion rate, followed by Gaul; Britain and Italy are more internally consistent in their diffusion rates.

This suggests that the adoption of innovation in Iberia and Gaul would take place faster than their geographical size might imply, and the adoption would not necessarily be as complete: to reach all individuals rapidly along the network structures of the itineraries suggests that there were concentrations in particular areas. In Britain and Italy, on the other hand, the adoption would be slower than their size might suggest, but the adoption would be more thorough (the structure of the itineraries reflects a more even distribution of population).

\section{Kilroy Was Here}

In World War II, 'Kilroy' left his mark everywhere that Allied soldiers travelled; the idea of 'Kilroy' was transmitted along their supply lines and communications channels (see Shennan 2002: 35-65 on social learning and the transmission of culture). Similarly, the diffusion of the practice of Roman monumen- tal inscriptions and the cultural phenomenon encapsulated by the notion of 'the epigraphic habit' (MacMullen 1982) seem to fit neatly into the framework suggested by this model. By comparing the density of inscriptions by province and region, using data available from the Corpus Inscriptionum Latinorum (CIL) (Harris 1989: 267-68; Woolf 1996: 36; Edmondson 2002: 44), it is possible to estimate roughly the number of inscriptions per $1000 \mathrm{sq} \mathrm{km}$. The problems of using such an indicator are discussed by Edmondson (2002: 43-47) and Prag (2002: 15-16), and are acknowledged by Harris himself. The two principal limitations are how this indicator masks the internal variability of epigraphic density within a district, and the general problems inherent in using the CIL as a source for quantitative data. Nevertheless, this indicator does capture some broad trends worth exploring. Given the model results above, we would expect that the variability of the density of epigraphic inscriptions (the fossilized trace of the spread of the 'epigraphic habit' throughout these regions) should be similar in Italy and Iberia, and similar in Gaul and Britain (figure 1 , above). The shape of the diffusion curves (figures 2 and 3, above) should correlate with the actual geographical distribution of inscriptions

In Italy, Campania has the highest number of inscriptions per $1000 \mathrm{sq} \mathrm{km} \mathrm{(411),} \mathrm{while}$ Lucania has the least (19) (figures from Harris 1989: 266-68, unless otherwise indicated; coefficients of variation ${ }^{4}$ calculated by the author). The average density for Italy is 114 per 1000 sq $\mathrm{km}$, with a coefficient of variation (C.V.) of $82 \%$. The figures for Iberia have been reevaluated by Edmondson (2002: 44) in the light of recent epigraphic work: he finds that some rates for Iberia should be roughly four times greater than those noted by Harris. Lusitania, in particular, seems to have had about 35 inscriptions per $1000 \mathrm{sq} \mathrm{km}$, while Baetica should be on the same order as Narbonensis, and Tarraconensis should be on the same order as Aquitania. In this case, the figures for the 
Iberian peninsula would be 35,56 , and 11 . This gives an average of 34 per $1000 \mathrm{sq} \mathrm{km}$, with a C.V. of $66 \%$ (alternatively, if we assume that each region is probably four times more dense than the figures recorded by Harris, following the pattern in Lusitania, the average would rise to 47 per $1000 \mathrm{sq} \mathrm{km}$, with a C.V. of 58\%). The C.V. suggests that, although not as dense as Italy, Iberia does seem to exhibit local variation in density of the same order of magnitude.

For the territories of Gaul, the average is 22 per $1000 \mathrm{sq} \mathrm{km}$, with a high of 56 per $1000 \mathrm{sq}$ $\mathrm{km}$ in Narbonensis. Britain has the lowest density, at 5.7 per $1000 \mathrm{sq} \mathrm{km}$. The C.V. for Gaul is $109 \%$. According to Woolf, when the clusters of inscriptions are plotted on the maps for Gaul and for Britain, there is a marked regionalism. In Britain, the inscriptions correspond very well with the sites of military occupation, particularly in the north. In Gaul, inscriptions are concentrated around Narbonensis, the lower Rhône Valley, the Rhineland, and central-eastern areas, again corresponding with a high level of militarization (Woolf 1996: 36 37; Blagg 1990: 27-28). A C.V. for comparison cannot be produced for Britain with these figures, although the regionalism apparent for both areas would seem to reinforce the idea that they are more similar to each other than they are to Italy or Iberia. The extremely high C.V. for Gaul is suggestive of Gaul's 'fragility', in terms of its network cohesion score as well. A more cohesive Gaul would presumably be a less variable Gaul. The disparity of Narbonensis, compared with the other territories of Gaul, as well as the regionalism of inscription use in Britain and Gaul, can also be seen as corresponding with the downward 'bumps' on the graph (Figure 4); once the message reached these areas, the diffusion of information accelerated again.

I am not suggesting that inscriptional density can be exclusively explained by the dynamics of the agent-based model and the network patterns in the itineraries. Even at this bare level of analysis, however, there are patterns in the archaeology that are highly reminiscent of those in the model (suggesting that the cognitive arrangement of space evidenced in the itineraries does have a role to play in any explanation), and thus this kind of analysis should represent a fruitful line of research. Prag's (2002) work on Sicily, in particular, could be compared with local itineraries for that province (both via an agent model and a network analysis) to study the regional dynamics of information diffusion within a single province.

\section{The Mediterranean and 'Small Worlds'}

The Mediterranean of course is the 'elephant in the room' in all of this discussion. By limiting it to the routes described in the itineraries, there has yet been no mention the greatest route of them all: an extension to this model should allow journeys across the sea, to and from ports with known connections (e.g. the towns and cities named in the mosaics in Ostia's Piazzale delle Corporazioni would be connected to Ostia). I suspect that the Mediterranean would function in network terms as a 'shortcut', connecting otherwise disparate parts of the network. Theoretically, this would have the effect of turning the communications networks into a 'small world', a very particular kind of network structure with a short average path-length and an extremely high degree of local clustering (Watts and Strogatz 1998; Watts 1999; 2000). 'Small worlds' are indistinguishable from ordinary networks at the local level: the difference lies in the way information or other flows travel from one side of a network to the other (i.e. the global behaviour).

In terms of the characteristics deduced for the various provinces based on their local network patterning, my overall conclusions would not be much altered by the inclusion of the Mediterranean as a shortcut, because the concern here has been chiefly with studying the local characteristics of particular sections of the itineraries. If the itineraries-as-com- 
munication-routes were studied from a global point of view, however, then the inclusion of the shortcut would necessarily change our understanding of behaviours mediated by this network (the Roman Empire). 'Small worlds' channel information and other flows in ways that lead to very interesting behaviour. In economic networks, for instance, they allow the concentration of wealth in very particular hands (is the wealth of cities connected to their network positioning?). In health networks, they help explain the rise and persistence of infectious diseases, and epidemiological models can be used for studying information and cultural change as well (Graham 2006a). Woolf (1992) contrasts the evidence for longdistance trade with regional trading in various goods throughout the empire, looking for evidence of empire-wide integration (which he finds only rarely). This seems characteristic of the sort of clustering that 'small world' network structures generally describe.

The other important point about 'small worlds' is that they are often found in complex systems, where higher-level structures emerge from the interactions of lower-level agents. Fulford (1992: 302) notes that the Mediterranean, and the way Rome used it to gather, concentrate and redeploy agricultural resources, gave her an opportunity for territorial expansion and enduring control which is perhaps unique among early imperial societies.' By allowing shortcuts, trade through these communication networks suggested by the itineraries could be modeled to explore the emergence of economic control over such a wide territory (for an agent-based model of economic stratification and control in Netlogo, see Gizzi et al. 2003)

\section{Agent-based Modeling and Roman Archae- ology: Some Beginnings}

The results of this study are necessarily restricted, but they do point to the potential of a methodology that considers the shape of interactions, the cognitive arrangement of geographical space, and context-as-process. The simulation itself is very basic. Extensions to the model might include greater intentionality (e.g. by having agents actively seek out others who have not been encountered, we could perhaps model the spread of religious ideas). Agents could contest ideas, allowing us to study the diffusion of competing ideologies. The environment in which these agents are moving (i.e. the routes from the itineraries) could be replaced with the plan of an ancient town, allowing us to study how information flowed through it: which houses or public spaces, for example, seem to attract the most interaction?

In terms of the itineraries themselves, it seems reasonable to conclude that they do reveal profound differences in the way that different regions operated. The intersecting and overlapping Mediterranean/Northern patterns ought to be significant in terms of the material culture and cultural development of these regions, while the overall similarities of speed point to the fundamental unity of the Roman Empire. The fragility of the networks (in terms of the perception of disruption) point to some possible consequences of relying on itineraries to navigate.

This work, although largely theoretical in nature, has methodological import for archaeology. First, there is the conceptual point to be made: the way that geographic space was conceived in antiquity could have had an effect on the way ideas and goods were distributed. The distribution maps of archaeological material that we prepare and analyze from our western mode of thinking about space might fundamentally misrepresent the ancient experience, and so we might miss the significance of what we find. If representing space as an itinerary was the convention of the day, can our archaeological analyses be modified to take that into account? For instance, the cost surfaces used in GIS analyses to model the dif- 
ficulty of moving around a landscape (see Bell et al. 2002, for an example explicitly dealing with communication routes) might perhaps be modified to ease movement along routes suggested by the itineraries.

Second, agent-based models allow us to ask 'what if?' questions, and to generate answers 'organically'. One could use the specific model presented here to ask whether the itineraries were used by long-distance traders, or rather whether products were traded hand-to-hand through local networks. In this case, an extension of it that included pottery manufacturing sites and divided the agents into producers and consumers could be used to track the trade and distribution of pottery, using the itineraries as the geographical framework. An output of the model might be an artificial distribution map of pottery types, which could then be compared with archaeological distribution maps; the combination of parameters in the model that created the best fit against the actual distribution would therefore provide insight otherwise unavailable, potentially transforming our understanding. Network analysis can help us understand the social structures of a society; an agent-based model can bring those structures to life.

\section{Notes}

1. For a general description of agent-modeling in 'human systems', see Bonabeau 2002. Agar 2003 discusses the potentials and perils of agent-modeling in the social sciences. Graham 2005a is an application of agent-modeling in Roman history, while Kohler et al. 2005 and Kohler 1995 extend the approach to the Anasazi of the American South-West. For general applicability of agent-modeling, see Kohler and Gumerman 2000. Doran et al. 1994 provide an example from the European Upper Palaeolithic.

2. Those who wish to explore the assumptions and limitations of this model may obtain a working copy (Graham 2005b), and the model code itself at http://home.cc.umanitoba. $\mathrm{ca} /$ grahams/itineraries.html. The programming platform is Netlogo (Wilensky 1999), from Northwestern University's Centre for Connected Learning.

3. Contrast the high penetration of the Imperial Cult and the Imperial family into the fabric of Gaul (Woolf 1998: 120-21) with the adoption of the Imperial Cult in central Spain (where it seems that it quickly penetrated deep into the hinterland of the region, being established by the late 1st century BC [Curchin 1996], and with the first appearance of an inscription to the Imperial numen in Britain in $133 \mathrm{AD}$ (Fishwick 1991: 413.

4. The standard deviation divided by the mean, and multiplied by 100 .

\section{Acknowledgments}

This research was made possible by the Canada Research Chair in Roman Archaeology, Lea Stirling, at the University of Manitoba, whose support is gratefully acknowledged. I would like to express my thanks to the anonymous reviewers and to JMA's co-editors, whose perceptive comments and critiques improved this paper enormously. Mark Lawall, Ray Laurence, Giovanni Ruffini, and Tamara Vaughan have seen this manuscript at various stages and their comments were invaluable. A version of this paper was presented at the 35th Annual Medieval Workshop, 'Cartography in Antiquity and the Middle Ages: Fresh Perspectives, New Methods' at the University of British Columbia on October 28th 2005. The comments and critiques offered by the participants at that workshop are gratefully acknowledged. I am in debt also to the instructors and participants at the Netlogo workshop at Mesa State College in Grand Junction, Colorado, in July 2005, for teaching me how to develop models in Netlogo. Mistakes are, of course, my own. 


\section{About the Author}

Shawn Graham is currently the Post-Doctoral Research Fellow in Roman Archaeology in the Department of Classics at the University of Manitoba. He completed his undergraduate degree at Wilfrid Laurier University in Waterloo, Ontario, Canada, and his postgraduate degrees at the University of Reading in the UK. His research interests range from artificial intelligence(s) in archaeology to the construction industry of Rome. He is working on a number of agent-based simulations of various aspects of Roman society and culture, including the emergence of social class, the robustness of Roman social networks (based on the prosopography of Roman brick stamps), and the emergence of trading networks. His fieldwork activities include time as a research assistant at the British School at Rome, excavations at Forum Novum and Silchester, and developing public archaeology and cultural resource management programmes in Western Quebec, Canada. His thesis on social networks and the complex dynamics of the Roman brick industry will be published as Ex Figlinis: The Network Dynamics of the Tiber Valley Brick Industry in the Hinterland of Rome (BAR International Series 1486; Oxford: John and Erica Hedges Ltd, 2006).

\section{References}

Adams, C., and R. Laurence (eds.)

2001 Travel and Geography in the Roman Empire. London: Routledge.

Agar, M.

2003 My kingdom for a function: modeling misadventures of the innumerate. Journal of Artificial Societies and Social Simulation 6.3. Internet Edition: http://jasss.soc.surrey.ac.uk/6/3/8.html.

Aldenderfer, $\mathrm{M}$.

1991 The analytical engine: computer simulation and archaeological research. In M. Schiffer (ed.), Archaeological Method and Theory Vol. 3: 195-248. Tucson: University of Arizona Press.
1998 Quantitative methods in archaeology: a review of recent trends and developments. Journal of Archaeological Research 6.2: 91-120.

Arnaud, P.

1988 L'origine, la date de rédaction et la diffusion de l'archétype de la Table de Peutinger. Bulletin de la société nationale des antiquaires de France (1988): 302-21.

Barabàsi, A.-L.

2002 Linked: The New Science of Networks. Cambridge, Massachusetts: Perseus.

Barabási, A.-L., and R. Albert

1999 Emergence of scaling in random networks. Science 268: 509-12.

Barrett, J

2001 Agency, the duality of structure, and the problem of the archaeological record. In I. Hodder (ed.), Archaeological Theory Today, 141-64. Cambridge: Polity Press.

Batty, M.

2003 Network geography: relations, interactions, scaling and spatial processes in GIS. Centre for Advanced Spatial Analysis, Working Paper 63. Internet Edition: www.casa.ucl.ac.uk/ working_papers63.pdf.

Bell, T., A. Wickham and A. Wilson

2002 Tracking the Samnites: landscape and communications routes in the Sangro Valley, Italy. American Journal of Archaeology 106: 169-86.

Blagg, T.

1990 Architectural munificence in Britain: the evidence of inscriptions. Britannia 21: 13-31. Bonabeau, E.

2002 Agent-based modeling: methods and techniques for simulating human systems. Proceedings of the National Academy of Sciences of the United States of America 99.10, Supplement 3: 7280-87.

Borgatti, S.

1999 Keyplayer Version 1.44. Nantick, Massachusetts: Analytic Technologies.

Borgatti, S., M. Everett and L. Freeman

1999 UCINET 6.0, Version 1.00. Nantick, Massachusetts: Analytic Technologies.

Brodersen, $\mathrm{K}$.

2001 The presentation of geographical knowledge for travel and transport in the Roman world: itineraria non tantum adnotata sed etiam 
picta. In C. Adams and R. Laurence (eds.), Travel and Geography in the Roman Empire, 7-21. London: Routledge.

Capelli, R., and F. Pesando

1991 Gli itinerary romani: repertorio bibliografico. In R. Capelli (ed.), Via Publicae Romanae: X Mostra europea del Turismo, artigianato e delle tradizioni culturali, Roma, Castel Sant' Angelo, 11-25 aprile 1991, 41-44. Rome: LeondardoDe Luca.

Cherry, J.F.

1977 Investigating the political geography of an early state by multidimensional scaling of Linear B tablet data. In J. Bintliff (ed.), Mycenaean Geography: Proceedings of the Cambridge Colloquium, September 1976, 76-82. British Association for Mycenaean Studies: Cambridge University Library.

Chorley, R., and P. Haggett

1969 Network Analysis in Geography: An Exploration in Spatial Structure. London: Arnold.

Cilliers, P.

1998 Complexity and Postmodernism: Understanding Complex Systems. London: Routledge.

Clark, E.

1992 Elite networks and heresy accusations: towards a social description of the Origenist Controversy. Semeia 56: 74-117.

Cuntz, O.

1929 Itineraria Romana, Vol. I: Itineraria Antonini Augusti et Burdigalense. Reprint 1990. Stuttgart: Teubner.

Curchin, L.

1996 Cult and Celt: indigenous participation in emperor worship in Central Spain. In A. Small (ed.), Subject and Ruler: The Cult of the Ruling Power in Classical Antiquity. Journal of Roman Archaeology Supplementary Series 17: 143-52. Ann Arbor: Journal of Roman Archaeology.

Doran, J., M. Palmer, N. Gilbert and P. Mellars

1994 The EOS project: modeling Upper Paleolithic social change. In N. Gilbert and J. Doran (eds.), Simulating Societies: The Computer Simulation of Social Phenomena, 195-221. London: UCL Press.

Duling, D.

1999 The Jesus movement and social network analysis (Part I: the spatial network). Biblical Theology Bulletin 29.4: 156-75.
Duncan-Jones, R.

1990 Structure and Scale in the Roman Economy. Cambridge: Cambridge University Press.

Edmondson, J.

2002 Writing Latin in the Roman province of Lusitania. In A. Cooley (ed.), Becoming Roman, Writing Latin? Literacy and Epigraphy in the Roman West. Journal of Roman Archaeology Supplementary Series 17: 41-60. Ann Arbor: Journal of Roman Archaeology.

Favro, D.

1996 The Urban Image of Augustan Rome. Cambridge: Cambridge University Press.

Fishwick, D.

1991 The Imperial Cult in the Latin West, II.1. Leiden: Brill.

Fulford, M.

1992 Territorial expansion and the Roman Empire. World Archaeology 23: 294-305.

Gilbert, N., and K. Troitzsch

2005 Simulation for the Social Scientist. 2nd edn. Maidenhead: Open University Press.

Gimblett R.

2002 Integrating Geographic Information Systems and Agent-based Modeling Techniques for Simulating Social and Ecological Processes. Oxford: Oxford University Press.

Gizzi, M., T. Lairson and R. Vail

2003 New wealth distribution. http://ccl.northwestern.edu/netlogo/models/community/new_ wealth_distribution. Modification to original model created by U. Wilensky. 1998 Wealth distribution http://ccl.northwestern.edu/netlogo/models/WealthDistribution. Center for Connected Learning and Computer-Based Modeling, Northwestern University. Evanston, Illinois.

Gould, P., and R. White

1974 Mental Maps. Harmondsworth: Penguin. Graham, S.

2005a Agent-based modeling, archaeology and social organisation: the robustness of Rome. The Archaeological Computing Newsletter 63: 1-6.

2005b An agent-based exploration of the Antonine Itineraries: model applet and code. http:// home.cc.umanitoba.ca/ grahams/itineraries. html.

2006a Who's in charge? Studying social networks 
in the Roman brick industry in central Italy. In C. Mattusch and A. Donohue (eds.), Acta of the XVIth International Congress of Classical Archaeology. Oxford: David Brown Book Company.

2006b The space between: places and connections in the Tiber valley. In H. Patterson (ed.), Mercator Placidissimus: The Tiber Valley in Antiquity. New Research in the Upper and Middle River Valley. (Proceedings of the Conference held at the British School at Rome, 27-28 Feb. 2004). Rome: Edizioni Qasar.

Hanneman, R.A., and M. Riddle.

2005 Introduction to Social Network Methods. Riverside: University of California, Riverside. Internet Edition: http://faculty.ucr.edu/ $\sim$ hanneman/

Harris, W.

1989 Ancient Literacy. Cambridge, Massachusetts: Harvard University Press.

Horden, P., and N. Purcell

2000 The Corrupting Sea: A Study of Mediterranean History. Oxford: Blackwell.

Kendall, D.G.

1971 Maps from marriages: an application of nonmetric multidimensional scaling to parish register data. In F.R. Hodson, D.G. Kendall and P. Tautu (eds.), Mathematics in the Archaeological and Historical Sciences, 303-18. Edinburgh: Edinburgh University Press.

1977 Computer techniques and the archival map reconstruction of Mycenaean Messenia. In J. Bintliff (ed.), Mycenaean Geography: Proceedings of the Cambridge Colloquium, September 1976, 83-87. British Association for Mycenaean Studies: Cambridge University Library.

Kohler, T.

1995 Agent-based modeling of Anasazi village formation in the northern American Southwest. http://www.ncgia.ucsb.edu/conf/SANTA_ FE_CD-ROM/sf_papers/kohler_tim/kohler. html

Kohler, T., and G. Gumerman

2000 Dynamics in Human and Primate Societies: Agent-Based Modeling of Social and Spatial Processes. New York: Oxford University Press.
Kohler, T., G. Gumerman and R. Reynolds.

2005 Simulating ancient societies. Scientific American 293.1: 76-84.

Laurence, R.

1998 Land transport in Roman Italy: cost, practice and the economy. In H. Parkins and C. Smith (eds.), Trade, Traders and the Ancient City, 129-48. London: Routledge.

2001 The creation of geography: an interpretation of Roman Britain. In C. Adams and R. Laurence (eds.), Travel and Geography in the Roman Empire, 67-94. London: Routledge.

2002 Roman Italy's urban revolution. In E. Lo Cascio and A. S. Marino (eds.), Modalità insediative e strutture agrarie nell' Italia meridionale in età romana, 591-609. Bari: Edipuglia.

Lewin, R.

1993 Complexity: Life at the Edge of Chaos. London: Dent.

Ling, R.

1990 A stranger in town: finding the way in an ancient city. Greece and Rome (2nd Series) 37.2: 204-14.

Lynch, K.

1960 The Image of The City. Cambridge, Massachusetts: MIT Press.

MacMullen, R.

1982 The epigraphic habit in the Roman Empire. American Journal of Philology 103: 233-46.

Mark, D., C. Freksa, S. Hirtle, R. Lloyd and B. Tversky

1999 Cognitive models of geographic space. International Journal of Geographical Information Science 13: 747-74.

Massey, D., J. Allen and S. Pile (eds.)

1999 City Worlds: Understanding Cities 1. London: Routledge.

Montello, D., S.I. Fabrikant, M. Ruocco and R. Middleton

2003 Testing the first law of cognitive geography on point-display spatializations. In W. Kuhn, M.F. Worboys and S. Timpf (eds.), Spatial Information Theory: Foundations of Geographic Information Science. Proceedings of COSIT '03. Lecture Notes in Computer Science 2825: 335-51. Berlin: Springer.

Müller, K.

2002 Ptolemaic settlements in space: settlement size and hierarchy in the Fayum. Archiv für 
Papyrusforschung und verwandte Gebiete 48.1: 107-25.

Prag, J.

2002 Epigraphy by numbers: Latin and the epigraphic culture in Sicily. In A. Cooley (ed.), Becoming Roman, Writing Latin? Literacy and Epigraphy in the Roman West. Journal of Roman Archaeology Supplementary Series 48: 15-32. Ann Arbor: Journal of Roman Archaeology.

Remus, $\mathrm{H}$.

1996 Voluntary association and networks: Aelius Aristides at the Asclepieion in Pergamum. In J. Kloppenborg and S. Wilson (eds.), Voluntary Associations in the Graeco-Roman World, 146-75. London: Routledge.

Richiardi, M., R. Leombruni, N. Saam and M. Sonnessa

2006 A common protocol for agent-based social simulation. Journal of Artificial Societies and Social Simulation 9.1. Internet Edition: http:// jasss.soc.surrey.ac.uk/9/1/15.html

Salway, B.

2001 Travel, itineraria and tabellaria. In C. Adams and R. Laurence (eds.), Travel and Geography in the Roman Empire, 22-66. London: Routledge.

Shennan, S.J.

2002 Genes, Memes and Human History: Darwinian Archaeology and Cultural Evolution. London: Thames and Hudson.

Spirn, A.W.

1998 The Language of Landscape. New Haven: Yale University Press.

Urry, J.

2000 Sociology Beyond Societies: Mobilities for the Twenty-first Century. London: Routledge.

Watts, D.

1999 Small Worlds: The Dynamics of Networks between Order and Randomness. Princeton Studies in Complexity. Princeton: Princeton University Press.

2000 A simple model of fads and cascading failures. Internet Edition: http://www.santafe.edu/sfi/ publications/Working-Papers/00-12-062.pdf

Watts, D., and S. Strogatz

1998 Collective dynamics of 'small-world' networks. Nature 393: 440-42.

Wilensky, U.

1998 Aids. http://ccl.northwestern.edu/netlogo/ models/AIDS. Center for Connected Learning and Computer-Based Modeling, Northwestern University. Evanston, Illinois.

1999 NetLogo. http://ccl.northwestern.edu/netlogo/. Center for Connected Learning and Computer-Based Modeling, Northwestern University. Evanston, Illinois.

Woolf, G.

1992 Imperialism, empire, and the integration of the Roman economy. World Archaeology 23: 283-93.

1996 Monumental writing and the expansion of Roman society in the Early Empire. The Journal of Roman Studies 86: 22-39.

1998 Becoming Roman: The Origins of Provincial Civilization in Gaul. Cambridge: Cambridge University Press. 